observation that the liberation of carbon monoxide occurs in the later stages of verdohæmochrome formation.

(2) Verdohæmochrome is far more stable than would be expected from the formulation as a hæmochrome... oxygen adduct. Compounds of this type have been assumed as intermediates in the autoxidation of hæmochromes, but have never been isolated. In contrast, verdohæmochrome exists under strongly reducing conditions, in neutral pyridine solution even in the presence of dithionite. Under such conditions reversibly bound oxygen would be removed, as is that of oxyhæmoglobin. Moreover, pyridine can be removed from verdohæmochrome, transforming it into moderately stable verdohæmin, from which verdohæmochrome can be reconstituted by the anaerobio addition of pyridine.

(3) Under no conditions has it been possible to reduce verdohæmochrome to $\alpha$-hydroxyporphyrin hæmochrome with its typical phyllotype-porphyrin hæmochrome spectrum. This ought to be possible if the structure assumed by Rackow was correct.

(4) While the evidence of Rackow for the persistence of a ring-conjugated system of double bonds is not convincing, it may be pointed out that an oxygenclosed system does not preclude ring-conjugation (of. the formula on p. 398, ref. 4).

Institute of Medical Research,

\section{R. LEMBERG}

Royal North Shore Hospitel, Sydney. Jan. 23.

1 Lemberg, R., Biochem. J., 29, 1322 (1985).

2 Rackow, B., HoppeSeyler's Z. physiol. Chem., 308, 66 (1957).

' Lemberg, $\mathbf{R}_{\text {;; }}$ and Legge, J. W.. "Hematin Compounds and Bile Pigments", 459 (Interscience P̈ub., New York and London, 1949). ' Foulkes, E. C., Lemberg, R., and Purdom, P., Proc. Roy. Soc., B, 138,386 (19̈51).

"Lemberg, R., "Reviews of Pure and Applied Chemistry", 6, 1 (1956)

- Ludwig, D. G., Blakemore, W. S., and Drabkin, D. L., Proc. Biochem. Soc., $58, \mathbf{P}$; Biochem. J., 68, No. 2 (1957). Blakemore, W. S., Ludwig, G. D., Forster, R. E., and Drabkin, D. L., Fed.
Proc., 16, 2 (1957).

\section{Temporary Nutritional Stress and Infertility in Mice}

Exposure to high environmental temperature has reduced the fertility in females of a number of species of animals ${ }^{1-s}$. Injections of cortisone or adrenocorticotrophic hormone into pregnant rats, rabbits and mice caused embryonic deaths ${ }^{5,6}$. $36-48 \mathrm{hr}$. starvation at the time of exposure increased the susceptibility of mice to Staphylococcus aureus infection". Temporary reduction in pasture 'quality' at the time of mating has been associated with bovine female infertility (McClure, unpublished data).

These facts suggested that a temporary nutritional stress at or about the time of mating may be able to cause infertility. To test this hypothesis, mice were subjected to transitory nutritional stress at or about the time of mating.

Two groups of mice were used : $(a)$ a control group of 19 female mice, which were given free access to food ; $(b)$ a treated group of 18 female mice, which were given free access to food except for three 48-hr. periods of complete starvation separated by two 48-hr. periods of normal feeding. The first starvation period commenced on the day male mice were introduced. Water was freely available to both groups at all times.

In the control group 9 out of 19 mice littered (59 young, average $6 \cdot 6$ ) from matings which were presumed to have occurred in the first ten days of the experiment. None littered from matings which may have occurred from the eleventh to the sixteenth day.

In the treated group none of 18 mice littered to possible matings in the first ten days of the experiment, that is, the period during which the mice were subjected to the nutritional stress. Seven mice littered (49 young, average 7) from matings which were presumed to have occurred within the six days after the period of starvation.

These results suggest that short periods of starvation at or about the time of mating may be detrimental to the fertility of mice, and that the residual effect of the starvation is short.

\section{T. J. MoClure}

Department of Agriculture,

Ruakura Animal Research Station, Now Zoeland. Feb. 6.

1 Sundstroem, E. G., Physiol. Rov., 7, 320 (1927).

Ogle, G., Amer. J. Physial., 107, 628 (1934).

Yeates, N. T. M., J. Agric. Sci., 48, 199 (1953).

'Shah, M. K., Nature, 177, 1134 (1956).

'Macfarlane, W. V., Pennycuik, Pamela R., and Thrift, E., J. Physiol. $185,451(1957)$.

- Robson, J. M., and Sharaf, A. A., J. Physiol., 116, 236 (1952) "Smith, J. Maclean, and Dubos, Rene J., J. Exp. Med., 108, 109

\section{Affinity of Neutral Red for Cells with Basophilic Cytoplasm}

Is earlier studies ${ }^{1,2}$ it was found that within half an hour of mice being injected with the dye neutral red, the cytoplasm of the exocrine cells of the pancreas became diffusely and homogeneously pink. A short time later, small reddish granules, the so-called 'neutral red granules', appeared. Shortly after injection these granules were discrete, but later took the form of aggregates immiscible with the cytoplasm. The single granules were about $0.7 \mu$ in diameter, the aggregates $2 \cdot 5-3 \mu$, and both were confined to the basophilic portion of the cell between the zymogen granules and the basement membrane. They did not occur among the zymogen granules and were never intranuclear. Vacuoles with these characteristics which might have been coloured by entrance of the dye into the cell were never observed in pancreas exocrine cells from animals not given the dye and it was concluded that the neutral red granules were 'new' formations. By the application of two techniques, Janus green ${ }^{3}$ in living cells and Altmann ${ }^{4}$ in fixed tissue, it was possible to distinguish the neutral red granules from apparently normal mitochondria.

In subsequent studies utilizing appropriate fixation and staining methods, we have confirmed Chlopin's ${ }^{8}$ observation that the neutral red granules are basophilic and pyroninophilic. This latter evidence that the granules contain ribonucleic acid is supported by our findings that basophilia is lost if the section is first exposed to ribonuclease. The nature of the particle apparently capable of extracting the dye from the general cytoplasm and concentrating it, leading to the formation of the intensely red granules, has not been established. It seems very possible that in the pancreas the re. sponsible element under normal conditions is submicroscopic, but is made microscopic only by its affinity for neutral red and subsequent swelling. In this connexion, it should be mentioned that there also occur in certain other cells ${ }^{6}$ essily visible cytoplasmic inclusions which stain in life with neutral red, but 